\author{
Cadernos de \\ ESTUDOS LINGǘĺSTICOS - (56.1), Campinas, Jan./Jun. 2014
}

\title{
A ALOMORFIA DOS NOMES AGENTIVOS TERMINADOS EM -DOR/-OR EM PORTUGUÊS
}

\author{
MAGNUN ROCHEL MADRUGA ${ }^{1}$ \\ IEL/UNICAMP
}

\begin{abstract}
RESUMO: Este trabalho discute a múltipla alomorfia presente na formação de nomes agentivos em português com terminações em dor, or, tor, sor, zor. A alomorfia dos agentivos é uma questão aberta na literatura e os trabalhos desenvolvidos preocuparam-se, prioritariamente, com as questões semânticas e aspectuais. Para tratar da alomorfia em específico, elaborou-se um experimento em que 15 participantes tinham que gerar um novo agentivo a partir de logatomas verbais em suas formas infinitivas e de particípio apresentados em uma sentença. Os resultados sugerem que a formação de nomes agentivos tem como base uma raiz e o tema verbal. Quando - dor é concatenado ao tema verbal o alomorfe -dor é superficializado; quando -dor é adjungido à raiz, este, em função do Princípio do Contorno Obrigatório, superficializa-se como -or. À luz da Morfologia Distribuída, propõe-se que os sufixos alomorfes desse tipo de agentivos em português sejam apenas -dor e -or.
\end{abstract}

Palavras-Chaves: Alomorfia; Agentivos; Morfologia Distribuida.

ABSTRACT: This paper discusses multiple allomorphy in agentive nouns, which appears in words ending in dor, or, tor, sor, zor in Portuguese. This allomorphy is an open question in the literature and previous studies have only addressed aspectual and semantic issues. In order to discuss the allomorphy, 15 participants were tested in an experiment. They were supposed to generate a new agentive from verbal nonwords in their infinitive and participle forms presented in a sentence. The results suggest that the formation of agentive nouns is based on a root and on a verbal stem. When -dor is merged to the verbal stem, the alomorph -dor goes to the surface; when -dor is adjoined to the root, it goes to the surface after applying the Obligatory Contour Principle, which generates - or on the surface form. Based on the Distributed Morphology approach, we propose that the allomorphs of such agentive suffixes in Portuguese are just -dor and -or.

Keywords: allomorphy, agentives; Distributed Morphology.

\section{INTRODUÇÃO}

Neste trabalho, procuro discutir a múltipla alomorfia presente na formação de nomes agentivos em Português, terminados em dor, or, tor, sor e zor. Com esses sufixos derivacionais, formam-se substantivos como treinador, cantor $e$ transmissor e adjetivos como salvador e enlouquecedor, por exemplo. Há uma discussão na literatura quanto ao status dos alomorfes e, em geral, considera-se

\footnotetext{
${ }^{1}$ Doutorando em Linguística da Universidade Estadual de Campinas (UNICAMP).
} 
-dor o morfema agentivo (OLIVEIRA, 2007, 2009; SAID ALI, 2001). Não há, ainda, nenhum trabalho sobre o português que se preocupe em discutir a múltipla alomorfia desses sufixos, a fim de entender como funcionam as formações de nomes de agente no estágio atual da língua.

Entre as principais referências sobre a formação de agentivos em dor, tor, sor, zor e or estão os trabalhos de Oliveira $(2007,2009)$. O objetivo dos dois trabalhos da autora, entretanto, é compreender a derivação desses nomes do ponto de vista sintático-semântico e, portanto, não se discute o status da múltipla alomorfia. Segundo a autora, as formações de nomes agentivos com -dor expressam os agentes dos verbos internos às formações e denotam eventualidades de nomeação ou designação. Esse sufixo nominal tem origem nas formas do particípio latino -(t)or, -(t)ōris/-(s)or, -(s)ōris, que, segundo Cunha(1986), adjunge-se apenas a temas verbais, resultando em nomes agentivos, nomes de instrumentos da ação designada pela base, bem como adjetivos agentivos.

Segundo Said Ali (2001), os itens terminados em -or, de origem verbal, introduziram-se na língua portuguesa por via erudita, tendo sido recebidos diretamente do latim, como nas palavras ator, autor, leitor, eleitor, agressor, compositor, professor etc. Para esse autor, o verdadeiro sufixo é -or, pois as consoantes /d/, /t/ e /s/ presentes nas formas dos sufixos nominais pertencem originalmente ao particípio passado latino. Oliveira (2009) não discute o status dos alomorfes -tor/-sor/-or e, conforme Said Ali (2001), assume que esses itens "passaram diretamente do latim para o português sem sofrer alterações históricas pelas quais passaram as raízes desses verbos” (OLIVEIRA, 2009, p. 194).

É difícil, porém, apenas a partir dos acontecimentos históricos contingentes à língua determinar as formas por ela escolhidas para figurarem como seus morfemas. Para evitar esse caminho, consequentemente, é preciso que se faça uma análise sincrônica a fim de vislumbrar os tipos de relações que esse sufixo estabelece em termos de estrutura linguística, bem como verificar a produtividade de uma forma ou outra em um determinado estado da língua. Em função disso, no presente estudo, faço uma discussão acerca do processo de alomorfia desse sufixo, procurando estabelecer generalizações para a formação de palavras agentivas desse tipo no português.

A questão geral que norteia este trabalho refere-se à compreensão do status das consoantes /t, d, s, z/ e sua relação com a múltipla alomorfia dos agentivos. Assim, estabelece-se como objetivo verificar se essas consoantes fazem parte do sufixo, da raiz ou se podem ser concebidas como consoantes epentéticas na derivação. Com isso, teremos condições de discutir não só a alomofia, mas também o processo derivacional de uma forma geral. O trabalho será desenvolvido com vistas a responder às seguintes questões: a) a formação de agentivos em -dor, -tor, -sor, -zor e -or se dá a partir de qual base?; b) qual a relação que eles estabelecem com a base?; c) como a Morfologia Distribuída pode lidar com a alomorfia dos agentivos em Português? A hipótese a ser testada na presente pesquisa é de que a múltipla alomorfia do morfema sufixal é apenas aparente. A alomorfia, seguindo esta hipótese, ocorreria somente entre -dor e -or; e as consoantes /t/ e /s/ de -tor e -sor fariam parte da raiz e não do sufixo. Nesse sentido, a formação de nomes de agentes relacionar-se-ia, também, a um processo alomórfico de raiz. 
Para testar essa hipóstese, elaborou-se um experimento cuja tarefa dos participantes era gerar um nome agentivo em dor, tor, sor, zor, or a partir de dois estímulos verbais - infinitivo e particípio - dados em uma sentença. Os resultados parecem sugerir que o alomorfe produtivo em português seja, de fato, -dor. Com esses achados, tem-se condições de sugerir uma nova proposta para o problema dessa múltipla alomorfia no estágio atual da língua portuguesa.

\section{A MÚLTIPLA ALOMORFIA DOS AGENTIVOS NO PORTUGUÊS}

No caso dos agentivos do Português, a alomorfia sufixal acontece seguindo um paradigma que tem como base o tema verbal. Entretanto, em alguns casos, a base do agentivo parece ser o particípio passado irregular e, em outros, apresenta uma base incerta de derivação.

Tabela 2: Verbos e Particípio Passado com respectivos agentivos do Português

\begin{tabular}{ccc}
\hline Infinitivo & Particípio & Agentivo \\
\hline treinar & treinado & treinador \\
contar & contado & contador \\
vender & vendido & vendedor \\
benzer & benzido/bento & benzedor \\
torcer & torcido & torcedor \\
polir & polido & polidor \\
instituir & instituído & instituidor \\
\hline
\end{tabular}

Os casos apresentados na Tabela 2 evidenciam que o sufixo agentivo -dor tem como base o tema verbal. Tal aspecto pode ser constatado a partir do que acontece com verbos 'benzer' (regular), 'torcer' e 'vender', casos em que a forma derivada agentiva apresentou a mesma forma da vogal temática de segunda conjugação. Caso as formas fossem derivadas do particípio passado, esperar-se-ia encontrar formas como *benzidor, *torcidor, *vendidor para os casos com morfema -dor.

Para os outros casos das terminações em tor, sor, zor, or, as relações entre as terminações e a base não são regulares, podendo estar ligadas à raiz, ao partícipio e até mesmo a uma base incerta. Vejamos o paradigma a seguir:

Tabela 3: Verbos e Particípio Passado com respectivos agentivos e base

\begin{tabular}{cccc}
\hline Infinitivo & Particípio & Agentivo & Base \\
\hline pintar & pintado & pintor & raiz \\
cantar & cantado & cantor & raiz \\
confessar & confessado & confessor & raiz
\end{tabular}




\begin{tabular}{cccc} 
eleger & elegido/eleito & eleitor & particípio irregular \\
suspender & suspendido/suspenso & suspensor & particípio irregular \\
deter & detido & detentor & incerta \\
proteger & protegido & protetor & incerta \\
compor & composto & compositor & incerta \\
opor & oposto & opositor & incerta \\
transmitir & transmitido & transmissor & incerta \\
\hline
\end{tabular}

Na Tabela 3, podemos ver que os agentivos formados pelos alomorfes -tor, -sor e -or apresentam diferentes bases. É importante notar que em nenhum desses casos a base é o tema verbal, tal como acontece com -dor. Ao contrário, os exemplos apresentam como base a raiz, o particípio irregular e há ainda casos em que não é possível determiná-la. Todas essas formas possivelmente foram herdadas do supino latino, cuja terminação era -tum e -sum, que naquela língua tinham estrutura idêntica a dos nomes de ação (SAID ALI, 2001; OLIVEIRA, 2009).

Tal fato nos permite perseguir a hipótese de o português ter herdado essas formas do latim tal como estão dadas sincronicamente, fazendo, entretanto, uma reanálise da base formadora de nomes de agentivo do grupo -tor, -sor e -or. Se assim for, teríamos dois grupos básicos nesse tipo de derivação: o primeiro cuja base é o tema verbal, e o segundo tendo como base uma raiz. Esse segundo grupo, mais específico, seria formado por formas especiais da língua, não sendo esse tipo de processo derivacional produtivo no estado atual do sistema, o que não obsta, porém, de terem essas formas altas frequências de uso.

Antes de testarmos essa hipótese, convém apresentarmos a análise de Oliveira (2007) para a formação de agentivos com o sufixo -dor, -tor, -sor, -zor, -or a fim de entendermos a necessidade de avanços nos estudos sobre esse tipo de formação de palavras no português.

\section{AGENTIVOS NO PORTUGUÊS: A ANÁLISE DE OLIVEIRA $(2007,2009)$}

Para Oliveira (2007, 2009), as formações agentivas em -dor, -tor, -sor carregam um conteúdo durativo e possuem restrições semântico-aspectuais impostas pelas raízes e pelo morfema nominal. As raízes verbais às quais o sufixo se adjunge referem-se a ações-processos e denotam imperfectividade, o que, segundo a autora, seria a razão de essas selecionarem o morfema [+agentivo/ causativo] com aspecto durativo. Nas formações derivadas interagem, portanto, as propriedades semântico-aspectuais da forma verbal e do morfema derivacional (OLIVEIRA, 2007, p.11). O diagrama arbóreo apresentado pela autora demonstra tais propriedades desse tipo de derivação. 


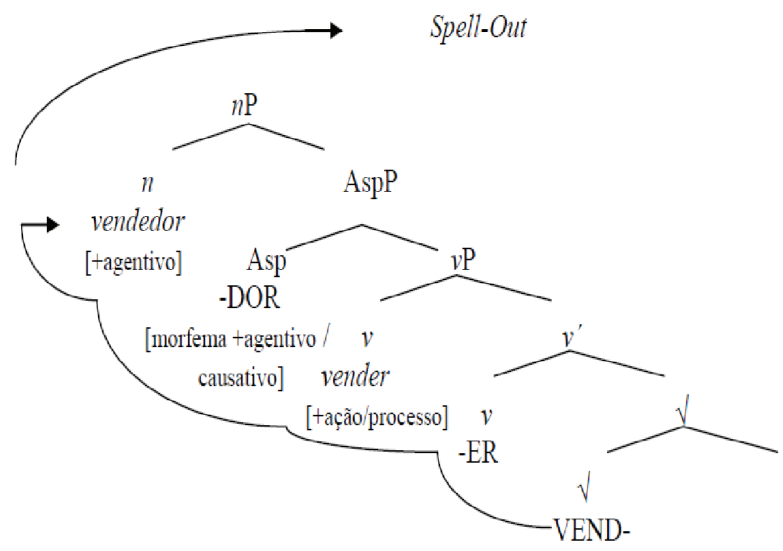

Nos termos da autora, a derivação ocorre da seguinte maneira:

$1^{\circ}$ ) a raiz $\sqrt{ }$ VEND- entra na derivação e é concatenada ao morfema -ER, inserido no núcleo funcional verbalizador $\mathrm{v}$, formando vender, que tem o traço aspectual [+ação-processo]; $2^{\circ}$ ) o morfema -DOR, inserido no núcleo funcional Asp, carrega o traço [+agentivo/causativo] e é semanticamente compatível com o traço semântico [+ação/processo] da raiz; $3^{\circ}$ ) a raiz vender concatena-se ao morfema -dor, que preenche a exigência semântica de agentividade; $4^{\circ}$ ) na parte fonológica da derivação, o núcleo funcional nominalizador $\mathrm{n}$ atrai a forma [vender + -dor], que se move para incorporar-se a n, formando vendedor, que tem o traço semântico [+agentivo] (OLIVEIRA, 2007, p. 7).

Em termos sintáticos, conforme o estudo de Oliveira (2007), as estruturas derivadas têm significados predizíveis a partir dos significados de suas partes, ou seja, denotam neste caso duração da agentividade. Ainda, para ela, a variedade de categorias lexicais revela que a [raiz + morfema verbalizador +-dor/-tor/-sor] é acategorial, já que aceita morfemas formadores de nomes $(n)$ e de adjetivos (a). Nesse sentido, a morfologia derivacional seria sintática e não lexical, embora deva desobedecer às restrições semânticas impostas pelas raízes e pelos morfemas.

A análise de Oliveira (2007) é extremamente interessante para que se incorpore a informação semântico-aspectual na derivação. No entanto, a autora apega-se somente a esse aspecto para desenvolver sua análise. Outro ponto a ser levantado é o fato de a autora não considerar a alomorfia sufixal e afirmar que a derivação na formação de agentivos se dá com a fórmula [raiz + morfema verbalizador + -dor/-tor/-sor]. Embora não seja esse o objetivo de sua pesquisa, tal questionamento é necessário, visto que as formas-base envolvidas em palavras com -tor/-sor (a autora não considera -or como uma outra forma possível) são totalmente distintas das formas com -dor.

É nítido que as palavras terminadas em tor/-sor, e aqui incluímos -or, têm diferentes bases de derivação e, nesses casos, não têm como base o tema verbal. Se assim de fato for, não é possível fazer a generalização sugerida por Oliveira (2007); ao contrário, é necessário rediscutir esse tipo de formação no português. Antes disso, porém, considero importante analisar como se dá esse 
tipo de derivação em uma outra língua latina, o italiano, a fim de investigar se a derivação desse tipo agentivo apresenta a mesma regularidade que o português. Para isso, apresento na seção seguinte o trabalho de Tucker (2000), cuja escolha para discussão aqui, dentre os vários que tratam o tema, deu-se pela metodologia experimental empregada pela autora, a qual, embora diferente da que emprego neste estudo, melhor se relaciona com a análise que faço. Além disso, o trabalho da autora, por tratar de uma língua da mesma família do português, que envolve, aparentemente, as mesmas questões na formação de agentivos, torna os resultados comparáveis e permite se discutir um aspecto que, possivelmente, é uma característica das línguas latinas, nesse caso em específico, de formação de palavras.

\section{FORMAÇÃO DE AGENTIVOS NO ITALIANO}

Tal como acontece no português, a formação de nomes de agente no italiano apresenta também uma face regular e previsível e outra irregular e imprevisível. A tradição dos estudos sobre o italiano considera que esse tipo de formação de palavras é resultado da adjunção do sufixo agentivo -ore à raiz do particípio do verbo sem a marca final de gênero - $o$. Para a maioria dos verbos em italiano, o particípio passado é fonologicamente previsível, bem como a formação de agentivos, que segue o seguinte paradigma.

Tabela 4: Verbos e Particípio Passado com respectivos agentivos e base no italiano

\begin{tabular}{cclc}
\hline Infinitivo & Particípio & Agentivo & \\
\hline lavorare & lavorato & lavoratore & "trabalhar" \\
acquisire & acquisito & acquisitore & "adquirir" \\
\hline Fonte: Tucker (2000, p. 7) & &
\end{tabular}

No entanto, alguns dos agentivos são construídos a partir do particípio, como acontece nos exemplos a seguir:

$\begin{array}{lll}\text { "difundir" } & \text { invadir" } \\ \text { diffuso }>\text { diffusore } & \text { invaso }>\text { invasore } \\ \text { PART } & \text { AGENT } & \text { PART } \\ \text { AGENT } & & \end{array}$

Ainda conforme a autora, outros agentivos parecem aproveitar o conteúdo fonológico do infinitivo, como se vê abaixo:

\begin{tabular}{|c|c|c|c|c|}
\hline "fundir" & & "suspender" & & \\
\hline fondere > & fonditore & sospendere & $>$ & sospenditore \\
\hline $\begin{array}{l}I N F \\
A G E N T\end{array}$ & $A G E N T$ & & & $I N F$ \\
\hline
\end{tabular}


Cadernos de ESTUDOS LINGü̈ISTICOS (56.1) - Jan./Jun. 2014

Vários estudos tentaram dar conta da formação de agentivos no italiano, entre eles, destacam-se Dressler e Thornton (1991), Vogel (1993), Burzio (1998) e Tucker (2000). A maioria afirma serem -ore e -tore os morfemas agentivos. Enquanto -ore adjunge-se ao particípio, o sufixo -tore concatena-se à raiz do infinitivo. Vogel (1993) e Burzio (1998) afirmam que a base do agentivo pode ser tanto a raiz do particípio quanto a do infinitivo, enquanto Dressler e Thornton (1991) afirmam ser apenas raiz do infinitivo sem a vogal temática a fonte para a formação do infinitivo. O estudo de Tucker (2000) difere significativamente dos outros por seus achados e metodologia experimental, e em função disso será mais bem detalhado.

O trabalho de Tucker (2000) tem como objetivo determinar a correta base da derivação de nomes de agente, cujo processo no italiano envolve múltiplos alomorfes. Para isso, a autora realizou um estudo experimental que contou com dois testes, um de produção dos agentivos e outro de aceitabilidade. A tarefa do primeiro teste feito por Tucker consistiu na produção de nomes de agente a partir de verbos com particípio irregular. A lista contendo 107 verbos no infinitivo foi apresentada aos sujeitos; 78 deles eram verbos com particípio irregular e sem agentivos correspondentes; 29 verbos de primeira e terceira conjugação com particípio regular e agentivos totalmente predizíveis. Aos participantes, foi pedido que produzissem, para cada infinitivo, a forma agentiva terminada em -ore. Os resultados desse primeiro experimento evidenciaram que a base preferida advém do infinitivo, o qual representou por $62,7 \%$ das produções dos participantes. Nomes de agente formados como base no particípio resultaram em apenas 19,6\% e, ainda, nos casos em que os falantes produziram agentivos a partir do particípio, $11,7 \%$ foram baseados em um agentivo pré-existente, já também derivado do particípio e que com ele partilhava certa similaridade fonológica. Dos $6 \%$ restantes, 3,4\% corresponderam a formas não derivadas nem do infinitivo nem particípio e 2,6\% foram dados ilegíveis ou agentivos não terminados em -ore.

No segundo experimento, os participantes julgaram a boa formação dos nomes agentivos. Foi feito, então, um teste de aceitabilidade em que os verbos no infinitivo foram apresentados aos sujeitos seguidos de duas ou mais formas agentivas admissíveis no italiano. A partir disso, eles julgaram a sua boa formação em uma escala de 1 a 7 , sendo que o valor 1 indicava que a forma era completamente inaceitável e 7 completamente aceitável, ou seja, uma total má-formação ou total boa formação. Nesse teste, foram usados 87 verbos no infinitivo, todos com particípio irregular, porém, 61 deles sem agentivos atestados e 26 com agentivos já existentes. No julgamento da aceitabilidade, os agentivos com scores mais altos foram aqueles derivados do infinitivo. Esses obtiveram uma média de 4,87 na escala, enquanto os derivados do particípio apresentaram média de 2,89. Os agentivos que também obtiveram melhor avaliação na aceitabilidade foram aqueles que não possuíam ambiguidade com a base, ou seja, os que possuíam similaridade com apenas uma forma, ou infinitivo ou o particípio. 
Os resultados obtidos pela autora indicaram que a base principal para formação dos agentivos terminados em -ore no italiano é o tema verbal. Segundo ela, o tema verbal é a correta base para a derivação desse tipo de agentivo e o uso aparente de outras bases é feito de forma analógica, seja para agentivos gerados a partir de verbos com os quais partilham certa similaridade fonológica seja para formas derivadas lexicalizadas que possuem bases não-infinitivas.

Com base nos achados de Tucker (2000), desenvolveu-se uma metodologia experimental semelhante neste trabalho a fim de compararmos, posteriormente, os resultados do português e do italiano. Na seção seguinte, discorro sobre o método.

\section{MÉTODO}

\subsection{Experimento}

Utilizamos no experimento 48 logatomas, todos trissílabos, que seguiram a estrutura da formação verbal e foram, portanto, divididos quanto à sua conjugação. Para cada paradigma de conjugação foram criados 8 verbos, os quais foram divididos em dois grandes grupos (Grupos I e II). No Grupo I, figuram os novos verbos e seus respectivos particípios regulares, enquanto o Grupo II é formado pelos novos verbos e seus particípios irregulares. Essa divisão resultou em $48(8 \times 3 \times 2=48)$ estímulos para cada grupo. Ao total, o experimento contou com 96 estímulos ( 8 novos verbos $x 3$ conjugações $x 2$ grupos $x 2$ particípios). Embora tenha-se trabalhado com um grupo controle para que os participantes não captassem o objetivo do exeperimento, faltou ainda um outro grupo de distratores, de modo a diminuir qualquer possibilidade de generalização desse tipo. Esse é um problema metodológico que poderá ser resolvido apenas em um trabalho próximo.

Os logatomas verbais criados para o experimento foram todos trissílabos e seguiram a estrutura /CVC.'CV.C+[ar, er, ir]/ . A primeira sílaba foi fixada em CVC para que evitássemos uma densa vizinhança lexical (NEWMAN et al, 1997; TALER et al, 2010). Assim, evita-se que o participante faça associações entre um verbo real da língua, como poderia acontecer, por exemplo, com o verbo "carregar" e seu agentivo "carregador"; se por ventura, o estímulo fosse "carremar", o falante poderia, por associação lógica, gerar "carremador". Considerando que estrutura /CV.'CV.CV/ é altamente frequente em português, poderíamos obter resultados enviesados pela associação do logatoma com uma verdadeira palavra da língua.

Na seleção dos estímulos, controlou-se a consoante final da raiz. Assim, dos oito verbos de cada conjugação, quatro sempre apresentavam as consoantes $/ t, d$, s, z/ no final da raiz. Os outros quatro falsos verbos tiveram a função de grupo controle. A incorporação dessa variável pareceu interessante porque, conforme constatamos no português, muitos dos agentivos terminados em tor, sor e or estão adjungidos a uma raiz cuja consoante da borda direita é sempre uma coronal, como nos exemplos (a), (b) e (c): 


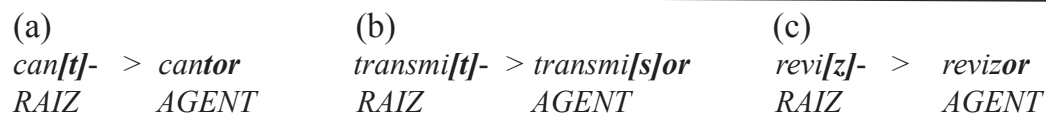

Sendo assim, a presença dessa variável foi pertinente para que investigássemos o papel da consoante final da raiz. Os estímulos foram apresentados aos participantes em sentenças como as que seguem:

(a) O ato de atirar almofadas para cima é chamado de genfetar. João Márcio tem genfetado todos os dias quando chega em casa. Poderíamos dizer que ele é um [resposta do participante].

(b) Paulo, de três anos, tem genfetado todo dia quando chega em sua creche. Ele gosta de genfetar porque acha divertido. Ele é um ótimo [resposta do participante].

O experimento baseia-se, portanto, no processo de generalização implicacional, que se caracteriza pela indução de uma regra geral a partir de uma implicação lógica entre dois conjuntos (HAMILTON, 1994; IDESTAM-ALMQUIST, 1995). Com esse tipo de experimento, temos condições de investigar qual base é utilizada para a formação dos agentivos, o infinitivo, particípio ou a raiz.

No experimento, como os participantes tinham acesso às duas formas verbais, foi preciso controlar a ordem ${ }^{2}$ de aparição do infinitivo e do particípio. Desse modo, para cada grupo, em 48 sentenças, a ordem de aparição dos logatomas foi InfinitivoParticípio e nas outras 48 a ordem foi Particípio-Infinitivo. Os estímulos foram aleatorizados na elaboração do experimento, mas não puderam ser aleatorizados por participante, dadas as condições da plataforma experimental utilizada.

\subsection{Materiais}

O experimento foi elaborado na plataforma Online Pesquisa ${ }^{3}$ e foi disponibilizado, via internet, para os participantes. A elaboração do experimento seguiu o padrão utilizado por Nevins e Rodrigues (2012).

\subsection{Participantes}

Completaram esse experimento 15 sujeitos $^{4}$, sendo 9 do sexo masculino e 6 do sexo feminino. Quanto à escolaridade, 3 participantes reportaram possuir

${ }^{2}$ A importância de se considerar a ordem dos novos verbos e particípios na sentença é crucial para se investigar um possível efeito de priming. O conceito de priming refere-se à ativação de partes de representações particulares ou de associações na memória antes de se desempenhar uma ação ou tarefa (BUSNELLO, 2007). Priming pode ser considerado um efeito em que se observa a influência de um evento anterior (prime) sobre o desempenho em uma situação posterior (alvo) (BLANK, 2013).

${ }^{3} \mathrm{O}$ endereço eletrônico do site é https://www.onlinepesquisa.com/

${ }^{4}$ No total, 75 sujeitos participaram da pesquisa, porém, como nem todos os participantes completaram o experimento, decidi utilizar somente os dados daqueles que o finalizaram. 
o ensino médio completo, 4 possuíam ensino superior incompleto, 6 tinham superior completo e 2 deles cursavam pós-graduação. $O$ único critério de exclusão considerado foi o participante ser estudante de cursos na área da Linguagem, como Letras ou Linguística.

\subsection{Análise Estatística}

A análise estatística dos dados foi realizada através do software R, versão 3.0.2 (R CORE TEAM, 2013). Para todas as interações entre as variáveis, os dados foram analisados com um teste de Qui-Quadrado, corrigido, quando necessário, pela correção de continuidade de Yates e pelo Teste Exato de Fisher. Além disso, adicionou-se uma medida de tamanho de efeito para que pudéssemos verificar a força de associação entre as variáveis. A medida utilizada é o V de Cramer, que se expressa em uma escala de 0 a 1. Para que a associação seja considerada aceitável, o valor de $\mathrm{V}$ deve ser igual ou maior a 0,20. Em casos de tabelas de contigência $2 \times 2$, o V de Cramer equivale ao Coeficiente Phi, que varia entre -1 e 1 ; neste caso, valores entre $-0,3$ e $+0,3$ são consideradas associações muito fracas ou inexistentes.

\section{DESCRIÇÃO E ANÁLISE DOS RESULTADOS}

Com o experimento suprarreportado, objetivo investigar o modo como os falantes de português constroem os nomes agentivos terminados com o morfema -dor/-tor/-sor/-zor/-or. Ao melhor entendermos o funcionamento da formação do agentivo, teremos condições de entender como esses alomorfes se relacionam com a base a que se adjugem.

A fim de analisarmos esse processo derivativo, consideramos os seguintes fatores apresentados de (a) a (g). Os parentêses referem-se às siglas utilizadas nos gráficos.

a) base do agentivo: raiz (R), infinitivo (I) ou particípio (P);

b) ordem dos logatomas verbais:

Particípio $(\mathrm{P}) \rightarrow$ Infinitivo (I) ou Infinitivo (I) $\rightarrow$ Particípio (P);

c) terminação da raiz: coronal $(\mathrm{C})$ ou outra $(\mathrm{O})$;

d) conjugação verbal: primeira (1), segunda (2) ou terceira (3) conjugações;

e) tipo de particípio: particípio irregular (I) ou regular (R);

f) escolaridade: ensino médio (EM), superior incompleto(SI), superior completo (SC) ou pós-graduação (PG); e

g) gênero: masculino (M) ou feminino (F). 
Cadernos de ESTUDOS LINGü̈ISTICOS (56.1) - Jan./Jun. 2014

Tabela 5: Frequência Relativa das Respostas dos Participantes

\begin{tabular}{|c|c|c|c|c|c|c|c|c|c|c|}
\hline & \multicolumn{5}{|c|}{ Base } & \multicolumn{2}{|c|}{ Terminação } & \multicolumn{3}{|c|}{ Conjugação } \\
\hline & Inf & Incerta & NSA & Part & Raiz & Cor & Outra & 1 & 2 & 3 \\
\hline DOR & 0,56 & 0,07 & 0,01 & 0,05 & 0,02 & 0,34 & 0,38 & 0,3 & 0,21 & 0,2 \\
\hline OutraClasse & - & - & 0,13 & - & - & 0,06 & 0,07 & 0,03 & 0,05 & 0,05 \\
\hline OutroMorfema & . & . & 0,1 & . & - & 0,06 & 0,04 & 0,04 & 0,04 & 0,03 \\
\hline \multirow[t]{3}{*}{ OR } & 0,01 & . & $\cdot$ & . & 0,4 & 0,04 & 0,01 & 0,01 & 0,02 & 0,03 \\
\hline & \multicolumn{4}{|c|}{ Escolaridade } & \multicolumn{2}{|c|}{ Genero } & \multicolumn{2}{|c|}{ TipoDeParticípio } & \multicolumn{2}{|c|}{ Ordem } \\
\hline & EM & $P G$ & SC & SI & $F$ & $M$ & Irreg & Reg & I.P & P.I \\
\hline DOR & 0,11 & 0,12 & 0,28 & 0,21 & 0,2 & 0,51 & 0,32 & 0,39 & 0,4 & 0,31 \\
\hline OutraClasse & 0,02 & - & 0,1 & 0,01 & 0,07 & 0,07 & 0,06 & 0,07 & 0,07 & 0,06 \\
\hline OutroMorfema & 0,03 & 0,01 & 0,04 & 0,03 & 0,04 & 0,06 & 0,04 & 0,06 & 0,06 & 0,05 \\
\hline OR & 0,01 & - & 0,02 & 0,02 & 0,01 & 0,04 & 0,04 & 0,02 & 0,02 & 0,03 \\
\hline & & & & & $=898$ & & & & & \\
\hline
\end{tabular}

$\mathrm{Na}$ Tabela 5, apresentam-se as frequências relativas das respostas dos participantes. As células com traço significam que não houve nenhuma ocorrência para aquela combinação. As categorias "Outro Morfema" e "Outra Classe" foram inseridas porque, em alguns casos, os participantes utilizaram um outro morfema agentivo ou mesmo outro morfema no lugar de derivações em -dor e -or. A categoria "Outra Classe" foi utilizada para etiquetar as formas em que o participante utilizou uma outra categoria nominal, como um adjetivo não agentivo, por exemplo. Ao total, foram 898 respostas, porém, para a análise estatística, foram utilizados 438 dados. Essa diminuição se dá pelo fato de que a combinação de alguns níveis não obteve nenhuma ocorrência e, também, porque foram eliminadas da análise as ocorrências dos níveis "Outra Classe"e "Outro Morfema".

No que se refere à associação com a base ${ }^{5}$, a forma de base escolhida é majoritariamente o infinitivo ${ }^{6}$, quando o morfema é -dor; enquanto o alomorfe -or adjunge-se preferencialmente a uma raiz. O teste de Qui-Quadrado reportou uma associação significativa entre o agentivo e o tipo de base a que ele se adjunge $\left(\chi^{2}=235,25, \mathrm{gl}=1, \mathrm{p}<0,001, \phi=0,74, \mathrm{~N}=438\right)$. No gráfico mosaico, podemos perceber a distribuição dos agentivos em funcão da base.

${ }^{5}$ Como todas as formas com -tor e -sor -zor, em nossos dados, sempre ocorreram adjungidos à raiz com terminação coronal $/ \mathrm{t}, \mathrm{d}, \mathrm{s}, \mathrm{z} /$ decidiu-se reportar apenas como -or cujo status será discutido adiante.

${ }^{6} \mathrm{O}$ particípio foi excluído da análise, pois não houve ocorrências com -or. 

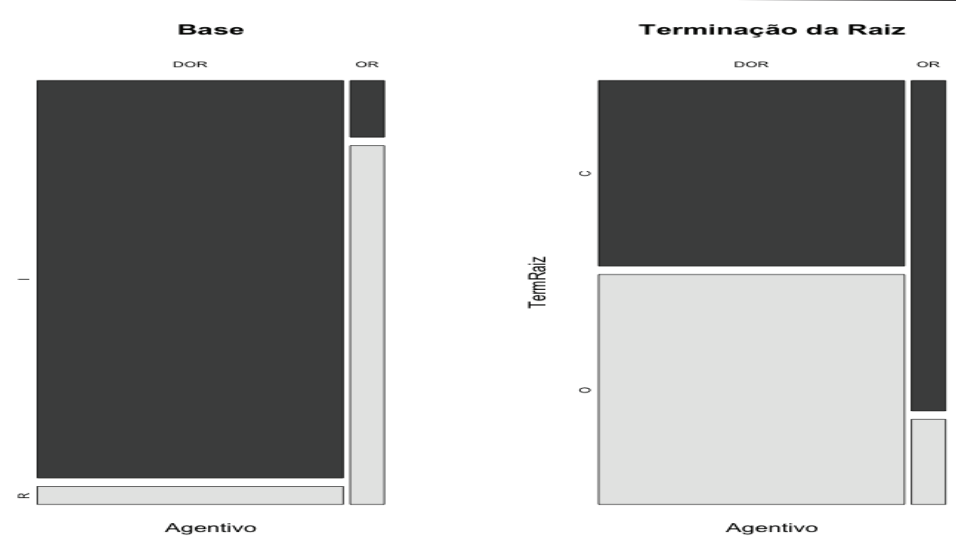

Figura 1: gráficos mosaicos para frequência absoluta dos morfemas agentivos em função da Base (painel direito) e da Terminaçao da Raiz (painel esquerdo).

Como podemos verificar na Tabela 5 e também no gráfico mosaico acima, o morfema -dor é empregado com qualquer tipo de consoante na borda direita da raiz. $\mathrm{O}$ mesmo, entretanto, não acontece para -or, que preferencialmente se anexa a uma raiz coronal. Como é possível depreender do painel direito da Figura 1 , as terminações -or associaram-se de forma expressiva às raízes, enquanto as formações -dor preservaram as vogais temáticas. Essa relação da terminação da raiz com os morfemas agentivos foi significativa $\left(\chi^{2}=17,91, \mathrm{gl}=1, \mathrm{p}<0,001, \phi\right.$ $=-0,21, \mathrm{~N}=438$ ).

A conjugação dos novos verbos também foi uma variável significativa $\left(\chi^{2}=\right.$ $24,41, \mathrm{gl}=2, \mathrm{p}<0,001, \mathrm{~V}=0,24, \mathrm{~N}=438$ ) na formação dos nomes agentivos. Os agentivos em -dor, embora distribuídos quase simetricamente nas três conjugações, apresentando uma pequena tendência à primeira conjugação. $\mathrm{O}$ contrário acontece com -or, cuja associação é preferencialmente as da segunda e terceira conjugações.
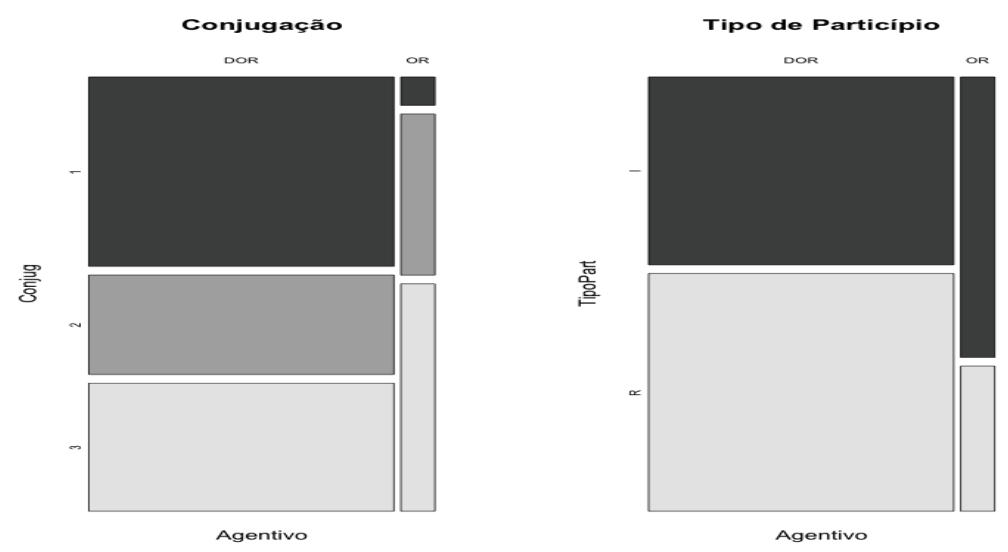

Figura 2: gráficos mosaicos para frequência absoluta dos morfemas agentivos em função da Conjugação (painel direito) e do Tipo de Particípio (painel esquerdo). 
Cadernos de ESTUDOS LINGḯlsTicos (56.1) - Jan./Jun. 2014

A variável "tipo de particípio" também se mostrou significativa $\left(\chi^{2}=6,67, \mathrm{gl}=\right.$ $1, \phi=-0,13, \mathrm{p}=0,009)$. Os substantivos agentivos terminados em -dor, como se pode inferir do gráfico, têm uma distribuição quase simétrica para as sentenças do experimento com particípios regulares e irregulares. Isso significa, portanto, que, para as derivações em -dor, a existência de um particípio - regular ou irregular - não é relevante, o que confirma a constatação anterior sobre a relação entre o morfema agentivo e a sua base. O alomorfe -or, entretanto, foi sensível ao particípio nos estímulos, e adjungiu-se à raiz quando a sentença do experimento apresentou um particípio irregular. Esse dado reflete o comportamento real da língua, como se pode verificar na Tabela 3, em que os agentivos em -tor e -sor têm como base um particípio irregular. A diferença aqui é que a base não é um partícipio irregular, mas a existência de um particípio irregular na sentença, o que nos permite verificar que a experiência do falante com língua é um fator de extrema relevância. Isso ainda é corroborado, quando se testa a variável escolaridade, visto que -or aparece majoritariamente nas respostas dos participantes com nível superior completo e incompleto.

A variável escolaridade mostrou-se significativa $\left(\chi^{2}=11.79, \mathrm{df}=3, \mathrm{p}=0,008\right.$, $\mathrm{V}=0,16, \mathrm{~N}=438$ ). A partir disso, então, podemos verificar que -dor distribui-se consideravelmente entre os quatro grupos (Ensino Médio, Superior Incompleto, Superior Completo e Pós-Graduação). Já o alomorfe -or apresenta uma distribuição muito maior nos grupos Superior Completo e Superior Incompleto, conforme podemos ver no gráfico abaixo:

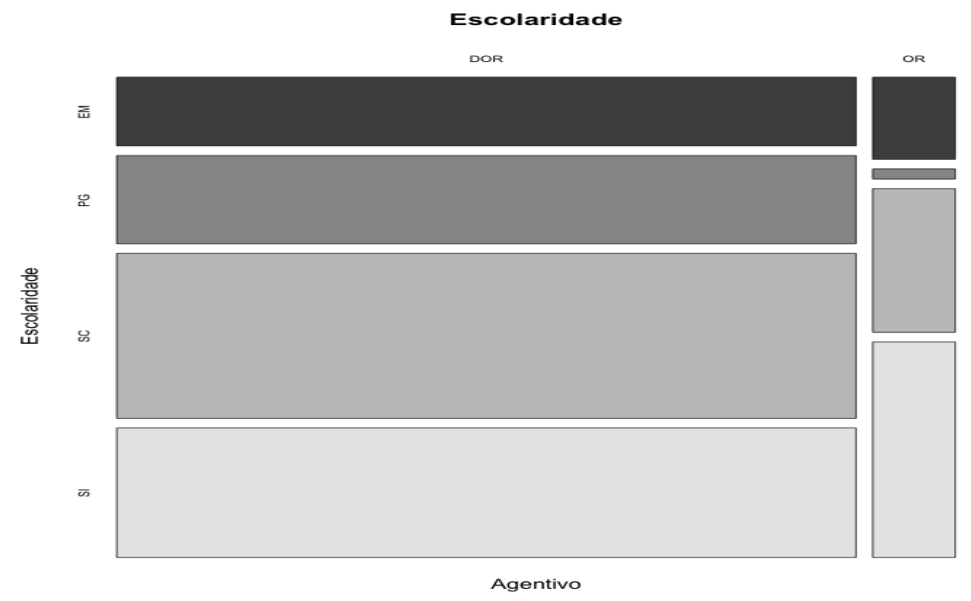

Figura 3: gráfico mosaico para frequência absoluta dos morfemas agentivos em função da Escolaridade.

A ordem dos logatomas verbais e particípios na sentença, $\mathrm{P} \rightarrow \mathrm{I}$ ou $\mathrm{I} \rightarrow \mathrm{P}$, não foi significativa ( $\chi^{2}=1,82, \mathrm{gl}=1, \mathrm{p}=0,17, \mathrm{~N}=438$ ). Assim, pode-se dizer que um possível efeito de priming não se mostrou relevante, ou seja, a informação mais recente dada na sentença não influenciou os participantes em suas resposta-alvo. E assim como a ordem, o gênero dos participantes também não foi uma variável significativa $\left(\chi^{2}=3,27, \mathrm{gl}=1, \mathrm{p}=0,07, \mathrm{~N}=438\right)$. 
Em suma, as variáveis significativas e com forte associação são base, terminação da raiz e conjugação. As variáveis tipo de particípio e escolaridade, embora tenham apresentado significativas associações com a formação de agentivos, a força de associação não foi forte, ficando entre valores fracos e muito fracos. No caso da escolaridade, uma das razões para isso pode ser o desequilíbrio na distribuição dos sujeitos entre as categorias. Quanto ao tipo de particípio, a associação muito fraca é esperada, tendo em vista que os alomorfes -dor e -or, segundo nossa hipótese, adjugem-se ao tema verbal e à raiz respectivamente. Sendo assim, o tipo de partícipio não seria relevante para a seleção da alomorfe.

Com base nesses resultados do experimento, na próxima seção, analiso os achados desta pesquisa sob o escopo da Morfologia Distribuída, com especial atenção à proposta de Arad (2003). Esses resultados parecem ir ao encontro da proposta de Marantz (2000) e Arad (2003), segundo a qual formação de palavras pode ser formada de dois modos básicos: (i) a partir de uma raiz e (ii) a partir de uma palavra, ou seja, de uma raiz já concatenada a um núcleo formador de palavra.

Procuro, além de discutir, propor um modelo de derivação que diminui o número de sufixos alomorfes para apenas dois: -dor e -or.

\section{DISCUSSÃO E PROPOSTA À LUZ DA MORFOLOGIA DISTRIBUÍDA}

Através de um trabalho experimental, tentei demonstrar a relação que se estabelece entre o sufixo e as diferentes bases às quais ele se adjunge. Assim, foi possível constatar que, quando -dor é concatenado ao tema verbal, este se superficializa como alomorfe -dor. Quando o morfema -dor é adjungido à raiz, o almorfe -or passa à estrutura de superfície após a aplicação do Princípio do Contorno Obrigatório (McCarthy, 1986). Esta proposta será mais bem discutida no escopo da Morfologia Distribuída na seção que segue.

\subsection{Uma proposta para os agentivos em -dor e -or no Português}

A Teoria da Morfologia Distribuída (HALLE \& MARANTZ, 1993, 1994; HALLE, 1997; MARANTZ, 1997, 2000) é uma teoria de arquitetura da gramática que possui como principais as seguintes características: a inserção tardia, que é a inserção de material fonológico após a derivação sintática; a subespecificação dos itens de vocabulário, ou seja, as estruturas fonológicas não necessitam de especificação, somente os morfemas, nós terminais da estrutura sintática, são totalmente especificados; e estrutura sintática hierárquica em toda derivação, a estrutura da derivação é a mesma para processos sintáticos e morfológicos e apresenta os mesmos tipos de constituintes.

Além disso, antes de tudo, é preciso notar a diferença quanto à especificação fonológica dos morfemas abstratos (também chamados de f-morfemas) e da raiz (l-morfemas), aspecto tal que será importante para se compreender 
a proposta aqui empregada. Para Embick e Noyer (2001, 2004), o conteúdo de um morfema abstrato ativo na sintaxe consiste de traços gramaticais e semânticos, ou seja, não há especificação quanto ao conteúdo fonológico. $\mathrm{O}$ morfema abstrato é composto exclusivamente de traços não-fonéticos, tais como [agente] ou [plural], por exemplo, que só receberão conteúdo fonológico após a derivação sintática. Para esses autores, a raiz, por outro lado, é constituída de representações fonológicas e nelas incluem-se itens como $\sqrt{\text { PAT- ou }} \sqrt{\text { PINT-, }}$ por exemplo, que nada mais são que sequências de feixes de traços fonológicos e, em alguns casos, de traços diacríticos (distintivos) não-fonológicos, como os traços de classe, ou de índices abstratos para distinguir os homófonos (EMBICK E HALLE 2004b, p. 2).

Neste trabalho, seguimos a proposta de Arad (2003). Para a autora, há dois modos de formação de palavra, derivados, consequentemente, na sintaxe. O primeiro, que a autora chama de root-level, consiste na derivação de palavras a partir de raízes, sem material funcional; o segundo, word-level, é a derivaçao de palavras a partir de palavras, isto é, a partir de raízes já categorizadas por algum núcleo. Segunda a autora, um núcleo $X$ pode adjungir-se a uma raiz ou a uma palavra já existente (substantivo, verbo, adjetivo). Assim, se um núcleo $X$ adjungir-se a uma raiz, ele colaborará para a atribuição de uma interpretação para essa raiz. Se adjungido a uma palavra, nada acontecerá, já que a interpretação da palavra foi fixada pelo núcleo logo abaixo na estrutura e não pela raiz (ARAD, p.738, 2003).

a.

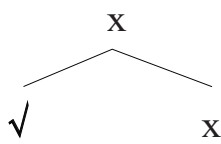

b.
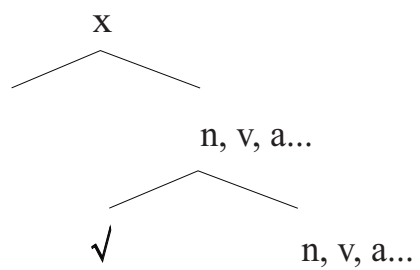

Os nossos dados parecem exibir esse comportamento. Como vimos, os alomorfes -dor e -or apresentaram derivações distintas, o que sugere que o processo derivacional possui diferentes estruturas. Com nossa proposta, conseguimos diminuir o número de alomorfes formadores de nomes de agentes no português de quatro para apenas dois, tais sejam: -dor e -or. Nesse sentindo, propomos que a formação de nomes de agentes esteja dividida em dois grupos, , o grupo -dor e o das derivações em -or. A formação dessas palavras seguem as seguintes derivações representadas através de esquemas árboreos: 
a) Grupo $-D O R$

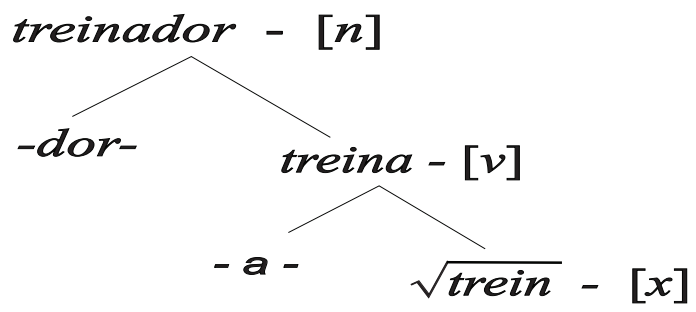

Nesses casos, o sufixo -dor não pode se adjungir à raiz, pois o siginificado desta já foi determinado quando houve a afixação da vogal temática verbal. A ele, está acessível apenas o último núcleo verbalizador e não a raiz. As derivações sufixais em -dor são, portanto, word-level. Segundo Arad (2003), as formações de palavras a partir de palavra consistem da concatenação de um afixo a uma já então palavra, ou seja, a uma unidade linguística categorizada; a interpretação já está fixada em um dado ambiente. Esse tipo de formação, segundo a autora, é, semanticamente, transparente e produtiva. De fato, é o que parece acontecer no português, tendo em vista que -dor é o morfema mais produtivo nesse tipo de derivação. Conforme os dados de nosso experimento, -dor é o principal afixo, o mais produtivo e tem como base o tema verbal.

Procendendo à análise de -or, assumimos que a formação dos nomes de agente com esse alomorfe é root-level. Desse modo, assume-se, consequentemte, que as bases não apresentam categoria gramatical, sendo a categorização feita pelo núcleo que com ela irá ser concatenado, que, no caso do agentivos, será sempre um nome. Em outras palavras, pode-se dizer que as raízes são categorias neutras e adquirem categoria morfossintática quando a elas for adjungido um núcleo categorizador (MARANTZ, 1997; EMBICK, 2000).

Nesse sentido, para o grupo -or, teríamos a seguinte situação:

b) Grupo $-O R$

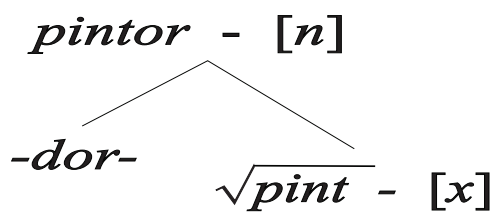

No exemplo acima, consideramos que a raiz /pint-/ torna-se nome. Consequentemente, uma palavra, uma vez que é concatenada com um núcleo nominalizador. O morfema [+ agente] -dor adjunge-se diretamente à raiz /pint-/. A existência de 'pintor' bloqueia a formação de *pintador, que é agramatical. Segundo Embick e Marantz (2008), o bloqueio acontece quando algumas formas tornam-se agramaticais pela existência de outra forma; essa competição tem lugar no nível da palavra, expressão ou frase. Assim, a existência de 'pintor' bloqueia o sistema de gerar '*pintador', já que as duas palavras teriam o mesmo significado. 
Vale ressaltar que na Morfologia Distribuída, há apenas conteúdo fonológico na raiz, ou seja, o que vai contecanar-se à raiz é o conjunto de traços que caracterizam o morfema. Neste caso, o traço [+agentivo] estará especificado. O morfema só ganha forma fonológica quando passa para o módulo da fonologia, situação em que as regras de reajustamento fonológico podem operar. Assim, quando - dor passa para o spell-out concatenado com a raiz, uma estrututa fonlógica não licenciada na língua é ajustada por OCP, cuja ação, neste caso, proíbe coronais adjacentes. A derivação teria os seguintes passos:

1) No componente morfológico, a raiz $\sqrt{\text { print }-}$ concatena-se com o morfema [+ agentivo];

2) No módulo fonológico, o morfema ganha conteúdo e realiza-se como -dor, surgindo então a forma não-licenciada *pintdor'. Além de receber acento, a palavra precisa satisfazer OCP, que proibirá sequências *[cor]-[cor]. Após a aplicação de OCP, surge então a forma "pintor”, que sofrerá Spell-Out.

A prevalência da consoante da raiz e não a do sufixo pode estar relacionada à manutenção da identidade da raiz sobre a identidade do sufixo. Beckman (1998), numa abordagem otimalista, afirma que os morfemas de raiz exibem comportamento privilegiado quando em situações de alternância do conteúdo fonológico. Isto é, a preservação da raiz é mais bem aceita nas línguas que a preservação do conteúdo dos afixos. A autora afirma que esse tipo de preservação de estrutura de um morfema em detrimento de outro é um dos efeitos do que chamou de Fidelidade Posicional.

Duas questões se colocam a partir da proposta que esboço neste texto: 1) Se de fato o português apresenta apenas os alomorfes -dor e -or (e não, -dor, -tor, -sor, -zor e -or), como a proposta lida com palavras como 'protetor' e ' detentor', cujo /t/ não está presente na raiz, por exemplo?; 2) Como explicar a alta produtividade de -dor se as derivações em -or apresentam estruturas menos complexas e, supostamente, mais econômicas?

Nos casos de palavras que apresentam uma base incerta de derivação, como as palavras 'protetor', por exemplo, a proposta que defendemos é que essas palavras possuem alomorfia de raiz (EMBICK \& MARANTZ, 2008, MARANTZ, 2008). Vejamos:

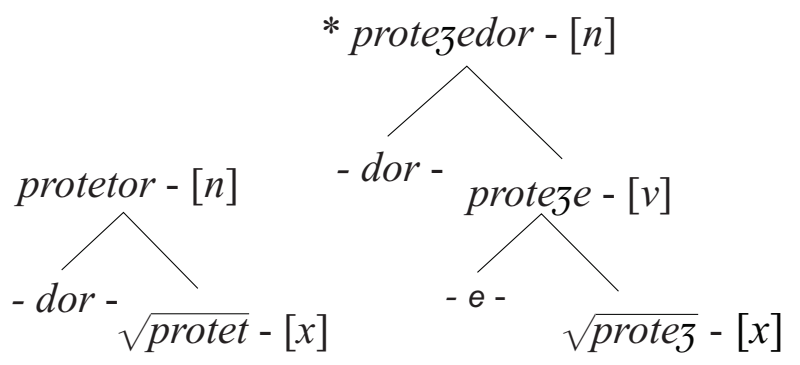


A existência do alomorfe -or dá-se apenas na superfície e é determinada pela raiz a que ele se adjunge, que também é uma raiz alomórfica. Consideramos que tanto /proteZ-/ quanto /protet-/ são raízes reais. A concatenação de /protet-/ com o morfema -dor é resultado do efeito de bloqueio de 'protegedor' e é, nesse sentido, uma relação arbitrária. Conforme Embick e Marantz (2008), a alomorfia de um núcelo [n] - em nosso caso, o morfema agentivo - anexado à raiz, é determinada pelas propriedades da raiz, o que não acontece com este mesmo núcleo que se adjunge a um domínio mais alto na estrutura, como é o caso de -dor. Para este, a relação de localidade é com outro núcleo [x] e não com a raiz; sendo assim, sua alomorfia não pode ser por ela determinada.

O fato de -or surgir apenas quando é adjungido a uma raiz com terminção em consoante coronal é confirmado pelo experimento, conforme já reportamos. O alomorfe -or só foi realizado quando o falante considerou como base da derivação a raiz terminada com as consoantes /t, d, s, z/. Conforme Arad (2003), esse tipo de formação de palavras a partir da raiz tende a exibir idiossincrasias e é, também, não produtivo porque a relação entre o núcleo categorizador e a raiz é uma relação arbitrária.

Com isso, conseguimos explicar a segunda questão, ou seja, a alta produtividade de -dor. O fato de nomes em -dor serem formados a partir de palavras (nos termos de Arad, word-level) permite que seus significados sejam mais predizíveis, ao contrário do nomes em -or, cujos significados são determinados pela sua relação arbitrária com a raiz. A estrutura das formações em -or, por si só, nada revela, se não entendermos a relação que a raiz faz com as derivacões a partir dela e com os alomorfes. Essa arbitrariedade expressa na relação entra a raiz e o alomorfe -or pode ser bem visualizada através das derivações em -dor, que apareceram mesmo quando a raiz terminava com as coronais /t, d, s, z/. Quando o morfema empregado é -dor, este não tem mais acesso à raiz e, portanto, a estrutura fonológica não representa qualquer impasse.

Assumindo que somente a raiz possui conteúdo fonológico especificado, a hipótese de uma restrição fonológica para a derivação dos agentivos em or parece ser plausível e não configura um problema para a análise. A raiz, apesar de ser livre quanto ao seu conteúdo, é sujeita a condições de licenciamento dadas por seus licenciadores (os morfemas abstratos ou f-morfemas) com os quais mantém relações estruturais, muitas vezes, arbitrárias.

A relação entre as estruturas propostas na análise e os resultados experimentais permitem confirmar que as formações word-level são mais produtivas nas línguas (Arad, 2003). Esse tipo de estrutura permite previsibilidade semântica, visto que seu conteúdo já está fixado quando um novo afixo se adjunge, como é o caso do -dor no português. Os achados experimentais desse estudo, apesar de serem inciais, instigam a discussão sobre o status do que se considera múltipla alormofia não só no português como em línguas da mesma família, que apresentam formações de agentivos semelhantes, como, por exemplo, o italiano, discutido neste trabalho, e até mesmo o espanhol. 


\section{CONSIDERAÇÕES FINAIS}

No presente estudo, procurei discutir a formação de agentivos terminados em -dor, -tor, -sor, -zor e -or. Embora a discussão que aqui faço seja apenas uma aproximação inicial com o problema da alomorfia nesse tipo de formação de palavras, procurei propor uma alternativa para a alomorfia desses sufixos no processo de derivação. A proposta reduziu de quatro alomorfes para apenas dois: -dor e -or e considera que o morfema seja, de fato, -dor. A análise realizada neste trabalho é uma tentativa de deixar mais econômica e preditiva a formação de nomes de agente em português. Para isso, utilizei o quadro teórico da Morfologia Distribuída (HALLE \& MARANTZ, 1993, MARANTZ, 2000 e trabalhos subsequentes), especialmente, o trabalho desenvolvido por Arad (2003).

Com o experimento empregado, sugeri que a derivação é diferente para casos em -dor e -or. No primeiro grupo, a derivação é feita a partir de uma palavra, que, nessa situação, é sempre a forma infinitiva do verbo, ou seja, o tema verbal. No segundo, a derivação é feita a partir da raiz, situação em que o morfema -dor é concatenado à raiz diretamente, sem passar por uma categorização. Argumento, seguindo Marantz (2000) e Arad (2003), que a alomorfia ocorre somente entre -dor e -or, sendo as consoantes /t/ e /s/ de -tor e -sor parte da raiz e não do sufixo. O morfema produtivo é -dor cuja base é o tema verbal e, portanto, o português segue a mesma tendência do italiano para a formação de nomes agentivos (cf. Tucker, 2000). A diferença crucial desta proposta para a de Tucker (2000) reside no fato de que, ainda, para o italiano a autora considera a múltipla alormorfia, enquanto nesta proposta, considero que no português a múltipla alomorfia é apenas aparente. Caso não fosse, esperar-seiam derivações em -tor e -sor com raízes, que não apresentassem uma consoante coronal em sua borda direita.

Parece que a alternativa mais preditiva é manter duas raízes e dois alomorfes. Assim, tem-se apenas dois alomorfes com base em derivacões distintas: a raiz, para -or, e para -dor, o tema verbal. No primeiro caso, o alomorfe -or resultante na superfície é fruto da operação do OCP no componente fonológico, que é um fenômeno operante nas línguas naturais. Portanto, uma análise como esta parece não comprometer a naturalidade da proposta.

Com o presente estudo, espero ter dado um passo incial à compreensão dos nomes agentivos em -dor e -or. A análise ora apresentada, é claro, tem caráter inicial e necessita consequentemente de mais testes para que se possa afirmar com maior acurácia o modo como os falantes de português derivam nomes agentivos com os sufixos aqui investigados. Seria interessante ainda que se fizesse uma discussão sobre o funcionamento desses agentivos em corpus de língua falada e escrita para que, assim, se pudesse investigar o fenômeno em situações menos controladas. 


\section{AGRADECIMENTOS}

Agradeço ao $\mathrm{CNPq}$ pela bolsa de doutorado concedida, processo número 140280/2012-0. Agradeço também aos participantes desta pesquisa e aos professores Filomena Sandalo, Luiz Carlos Schwindt e Andrew Nevins, cujas sugestões foram imprenscidíveis para o aprimoramento das análises aqui apresentadas. Agradeço também aos meus colegas que contribuíram com revisões e sugestões nas várias versões deste texto, são eles: Carina Fragozo, Cristina Prim, Diego Jiquilin, Fernanda Reis, Ivana Pereira Ivo e Maria Luisa Freitas.

\section{REFERÊNCIAS BIBLIOGRÁFICAS}

ARAD, Maya. Locality constraints on the interpretation of roots: the case of Hebrew denominal verbs. Natural Language and Linguistic Theory 21 (4): 737-78, 2003.

BECKMAN, J. Positional Faithfulness. Tese (Doutorado) - Amherst: University of Massachusetts, 1998.

BLANK, Cíntia. A influência grafo-fônico-fonológica na produção oral e no processamento de priming em multilíngues: uma perspectiva dinâmica. 2013. 225f. Tese (Doutorado em Letras). Programa de Pós-Graduação em Letras da UCPEL. Universidade Católica de Pelotas, Pelotas.

BUSNELLO, R. Efeito de priming subliminar no acesso ao léxico. Dissertação (Mestrado); Porto Alegre: PUCRS, 2007.

CUNHA, Antônio Geraldo. Dicionário etimológico - Nova Fronteira da língua portuguesa. Rio de Janeiro: Nova Fronteira, 1986.

CRYSTAL, D. Dicionário de Lingüística e Fonética. Rio de Janeiro: Jorge Zahar, Trad. Maria Carmelita Pádua Dias, 2000.

EMBICK, David. Features, syntax and categories in the latin perfect. In: Linguistic Inquiry. Cambridge, Massachusets: MIT Press, v.31, n.2, p.185-230, 2000.

EMBICK;HALLE, Morris. On the status of stems in morphological theory.Philadelphia: University of Pennsylvania e MIT, 2004b. p. 1-31.Manuscrito.

EMBICK; NOYER, Rolf. Movement operations after syntax. In: Linguistic Inquiry, Cambridge: MIT Press, 2001. v. 32, n.4, p. 555-595.

EMBICK; NOYER, Rolf. Distributed morphology and the syntax/morphology interface. In: RAMCHAND,G.; REISS, C. (ed.). TheOxford handbook of linguistic interfaces. Oxford: University Press,2004. p. 1-27.

HALLE, Morris. Distributed Morphology: Impoverishment and Fission. In: MIT Working Papers in Linguistics 30, p. 425-439, 1997.

HALLE, Morris.; MARANTZ, Alec. Distributed morphology and the pieces of inflection. In: HALE, K.; S. J. KEYSER (Ed.). The View From Building 20, Cambridge, Mass.: The MIT Press, 1993, p. 111-176.

HAMILTON, Robert. Is Implicational Generalization Unidirectional and Maximal? Evidence from Relativization Instruction in a Second Language. Language Learning. v. 44( 1), p. 123-157, 1994. 
HARLEY,Heidi.Thebipartitestructureofverbscross-linguistically.CONGRESSOINTERNACIONAL DA ABRALIN, Anais... UFMG, 2007.

HARLEY, Heid.; NOYER, Rolf. State-of-the-article: Distributed Morphology. Glot International 4.4, p. 3-9, 1999.

IDESTAM-ALMQUIST, Peter. Generalization of Clauses under Implication. Journal of Articial Intelligence Research v3, 1995. p467-489

MARANTZ, Alec. No Escape from Syntax: Don't Try Morphological Analysis in the Privacy of Your Own Lexicon. In: A. Dimitriadis, L. Siegel, C. Surek-Clark \& A. Williams, Proceedings of the 21st Penn Linguistics Colloquium. In: Working Papers in Linguistics, Philadelphia, p. 201-225, 1997.

MARANTZ, Alec. Roots: The Universality of Root and Pattern Morphology, paper presented at the conference on Afro-Asiatic languages, University of Paris VII, 2000.

McCARTHY, Jhon. OCP Effects: gemination and antigemination. Linguistics Inquiry. 17, p.207-263, 1986.

McCARTHY. No escape from syntax: don't try morphological analysis in the privacy of your own lexicon. In: DIMITRIADIS, A.; SIEGEL, L. et al. (eds.). University of Pennsylvania working papers in linguistics. Proceedings of the 21st Annual Penn Linguistics Colloquium, v.4, n.2, p. 201-225, 1997.

NEVINS, Andrew; RODRIGUES, Cilene. Naturalness Biases, 'Morphomes', and the Romance First Person Singular, 2012. Manuscrito Inédito.

NEWMAN RS, SAWUSCH JR, Luce PA. Lexical neighborhood effects in phonetic processing. J Exp Psychol Hum Percept Perform. 1997 Jun;23(3):873-89.

OLIVEIRA, S. M. O Sufixo Nominal Agentivo -Dor/-Tor/-Sor: uma Análise à Luz da Morfologia Distribuída. Eletras (UTP), v. 15, p. 1-12, 2007.

OLIVEIRA, Solange. Aspectos da Derivação Prefixal e Sufixal no Português do Brasil. 2009. 252f. Tese (Doutorado em Linguística). Programa de Pós-Graduação em Linguística da UFSC. Universidade Federal de Santa Catarina, Florianópolis.

SAID ALI, Manuel. Gramática histórica da língua portuguesa. 8 ed. rev. e atual. São Paulo: Companhia Melhoramentos, 2001.

SILVA, Everton Lourenço da. O Advendo da Morfologia Distribuída. . ReVEL, vol. 8, n. 14, 2010. Disponível em: http://www.revel.inf.br. Acessado em: 10 de setembro de 2013.

TALER, Vanessa; GEOFFREY, Aaron; STEINMETZ, Lauren; PISONI, David. Lexical Neighborhood on Spoken Word Reocgnition and Production in Healthy Aging. J Gerontol B Psychol Sci Soc Sci. 2010 September; 65B(5): 551-560.

TUCKER, Emily. Multiple Allomorphs in the formation of the Italian Agentive. Departamento de Linguística (Dissertação de Mestrado). UCLA, 2000.

R CORE TEAM. R: A language and environment for statistical computing. $\mathbf{R}$ Foundation for Statistical Computing, Vienna, Austria. URL http://www.R-project.org/, 2013.

SCHER, Ana. Paula.; MEDEIROS, Alessando de; MINUSSI, Rafael. Estrutura Argumental em Morfologia Distribuída. In: Naves, R. R.; Salles, H. M. L. (Org.). Estudos Formais da Gramática das Línguas Naturais. Goiânia: Cânone Editorial, p. 175-198, 2012. 